described by K. N. Preece (Morganite Research and Development, Ltd.).

Dr. S. Scholz (Philips, Aachen) discussed the rate of densification of refractories during hot-pressing and the effect on this of activating impurities, such as iron in tantalum carbide. A. W. Moore and Dr. D. A. Young (Imperial College of Science and Technology, London) showed how the anisotropy of electrical and thermal conductivity of well-oriented graphite had been utilized in the design of susceptors for induction heating, in the attainment of temperatures up to $3,400^{\circ} \mathrm{C}$. The radial pressure produced in a powder during its compaction in a die and its relation to compacted density were discussed by W. M. Long (Atomic Weapons Research Establishment, Aldermaston). The application of the electron microscope to ceramics, in the study of grain structure and surface texture, in the identification of crystalline fibres and fine particles by electron diffraction, and in following reactions, including the nitridation of silicon, was considered by Dr. S. N. Ruddlesden (British Ceramic Research Association).

The final session of the symposium was devoted to the applications of ceramics. Dr. A. J. Moulson and P. Popper (British Ceramic Research Association) first outlined the physical properties required of a ceramic for use as valve envelopes and windows, and the methods of measuring these properties in order to assess the suitability of a ceramic for valve applications. J. Free and Dr. D. Walsh (University of Oxford) described new uses of ceramics at ultrahigh frequencies ( $\mathrm{cm}$ and $\mathrm{mm}$ wave-lengths). Ceramics of low dielectric loss could be used as reflectors of microwave power, with the reflexion exceeding that of a pure silver surface, and experiments using titania were discussed. With non-linear dielectric materials it is theoretically possible to generate microwave power. The succeeding paper, by Dr. K. H. Kreuchen (Electrical and Musical
Industries, Ltd.), considered the special ceramic problems arising with the growing use of very-highpower valves in the transmitters of television stations, radar systems and particle accelerators, including the need for low surface resistivity to avoid charge build-up from the plasma, new shapes for waveguide windows to achieve broad-band performance, and secondary emission qualities. T. D. Davidson and J. Watkins (Morganite Research and Development, Ltd.) described the preparation of high-power microwave absorbing loads from silicon carbide and the variation of its semiconducting properties by the addition of silicon.

The theoretical and practical advantages of using ceramics in microwave tubes for particle accelerators and amplifiers, and the impressive performance obtained on a laboratory scale, were demonstrated by J. Free (University of Oxford), who stressed the need for the commercial development of new materials and predicted that acceler ators using ceramics would eventually outclass those of conventional type, on a cost basis, offering higher efficiencies and higher operating frequencies. In the magneto-hydrodynamic generation of electricity, materials are subjected to unusually severe conditions at temperatures above $2,000^{\circ}$ C. Dr. E. G. Wolff (Central Electricity Research Laboratories, Leatherhead) described the preparation and testing of some refractory borides, carbides, oxides and silicides as possible electrode and duct materials for such generators. The session closed with an illustration by W. F. Gibbons (Ferranti, Ltd.) of the ceramic-to-metal sealing technique and its application to problems in the field of nuclear engineering.

At the conclusion of the symposium the visitors toured the laboratories of the British Ceramic Research Association. The proceedings of the symposium will be published by the Academic Press in due course.
S. N. RUDdLesDen

\title{
SCIENTIFIC RESEARCH IN BELGIUM
}

$\mathrm{T}$ HE annual report of the Institute for the Encouragement of Scientific Research in Industry and Agriculture, Brussels, for 1961 records 65 grants totalling some 244.5 million francs distributed to some 229 investigators and 423 technicians*. A new grant of 21.5 million francs went to the Committee for Establishing the Soil and Vegetation Map of Belgium for its systematic study of the pedological character of the soil and completion of the pedological map of the kingdom. The Committee for the Study of the Solid State received a grant of 11.69 million francs towards research in progress in Prof. Dekeyser's laboratory at the University of Ghent on semiconductors, in the Laboratory of the Electrical Construction Works at Charleroi on the study of magnetic steel sheets, and in Prof. Brasseur's laboratory at the Gevaert factory on the improvement of photographic supports by perfecting tho method of acetylation; a further grant of $2 \cdot 15$ million francs was for continuation of the Committee's work on the welding of resinous materials, $1,787,500$ francs for research on the preparation of hard magnetic

* Institut pour 1'Encouragement de la Recherche Scientifique dans l'Industrie et l'Agriculture, Bruxelles. Rapport Annuel-Exercice Recherche Scientifique dans 1'Industrie et l'Agriculture, 1962.) materials, and one of 9 million francs for continuation of research on the mechanism of photographic processes and for work on new photographic processes. The Carbochemical Society of Tertre received a grant of 3.9 million francs for continuation of work on textile colours, and the Gevaert Photo Products Society 7.225 million francs for the study of photographic dyes and processes of colour photography.

A grant of 10.19 million franes went to the Committee on the Application of Isotopic Methods in Agronomic Research for research on the utilization of radioisotopes, and one of 9 million francs to the Research Centre of Gorsem for continuation of work on diseases and insect pests of various cultivated fruits with the view of a system of control, and also of research on the maturation and conservation of fruit and the influence of insecticides and fungicides on the physiology of the vegetables to which they are applied. The Technical and Scientific Centre of the Belgian Glass Industry received some 8.5 million francs for its research on the properties and homogeneity of glass, the mechanism of action of abrasives and on enamels for glass, while a grant of $7,886,000$ franes to the National Centre for Metallurgical Research was for analytical research by spectro- 
chemical and X-ray methods, physical metallurgy investigations, fundamental research by microcinematography on the mechanism of fracture, and various applied investigations; further grants of $2,795,000$ francs and 5,050,000 francs were for continuation of research on the mechanical properties of steel and on methods of utilization of steel, and one of $6,500,000$ francs for continuation of research on cobalt.

The Committee for the Study of the Problem of Nitrogen received a grant of $6,660,000$ franes for research on nitrogenous fertilizers in Belgium soils, including investigations on nitrification and absorption of nitrogen by vegetables. A grant of $6,027,000$ francs to the Centre for Biological Chemistry and Soil Colloids was for investigations on the transformation of organic matter in the soil, mineral colloids of the soil and on the cationic and organic manuring of soils. The Centre for Research into Forestry Biology received 5,590,000 francs for pedological, entomolog. ical and genetic research devoted towards improving the exploitation of forests and their conservation by natural regeneration. The Centre for Scientific and Technical Research on the Conservation of Vegetables received a grant of 5,222,000 francs for scientific and technical research on the cultivation of vegetables for conserving and on the conditions of conservation; 4,165,000 francs went to the Centre for Research on Agriculture for work on the mineral alimentation of vegetables, 3,700,000 francs to the Centre for Research on Vegetable Hormones, 3,210,000 francs to the Centre for Research on Parasitic Diseases of Domestic Animals, 2,835,000 francs to the Centre for the Study of the Forest Soils of Ardennes and Gaume; 5,470,000 francs to the Scientific and Technical Research Centre of the Explosives Industry and 5,174,079 franes to that of the Belgian Textiles Industry. Other grants included 3,350,000 franes to Dr. C. Janssen's Research Laboratory for research on the synthesis of ring systems with 3 or 4 atoms of carbon; 2,456,450 francs to the Laboratory of the Varnish, Paints, Printing Inks and Art Colours Industry and 2,835,000 franes to the Centre for the Study of Ornamental Plants for work on plant diseases and the cultivation of chrysanthemums and cyclamens. Other grants included 2,162,000 francs to the Technical and Scientific Centre of the Woodworking and Related Industries; $1,980,000$ francs to the Pedological Service of Belgium for researches on magnesium and on minor elements in vegetables; $1,840,000$ francs to the Foundation for Potato Research; 1,770,000 francs to the Committee for the Study of Apiculture; $1,525,000$ francs to the Committee for Strawberry Research; 1,160,000 franes to the Committee for the Scientific and Technical Study of Lactation; and 1,086,000 franes to the Belgian Institute for High Pressures.

\section{THE AUSTRALIAN DEFENCE STANDARDS LABORATORIES}

T HE function of the Australian Defence Standards Laboratories is outlined in the annual report for the year ended June $30,1961 *$. Its main concern is the application of scientific knowledge and research within the fields of chemistry, physies, metallurgy and engineering to problems arising in the design, manufacture, inspection and use of defence material. In addition, as its name implies, it is concerned with standards of measurement and standards of quality. The report deals with the general activities of the establishment and with some of the more important projects and investigations either completed or in progress in the fields of chemistry, metallurgy and physics.

In the Chemistry Division research has continued on the mechanism of the initial film formation on lead alloy anodes in sea-water, and the initial film has been shown to contain lead sulphate and some carbonate, in addition to lead chloride. Infra-red spectroscopy has been used for the study of a series of bis-pyridinium oximes. The cæsium bromide prism of the double pass spectrometer was calibrated for the far infra-red and a curve fitted to twenty points by orthogonal polynomial methods. The best fit was given by a cubic expression. The application of the Stokes parameters of electromagnetic radiation to the description of the state of polarization of Raman lines has been considered, and a procedure has been developed for the calculation of the intensity ratios and depolarization factors. The new apparatus of Lench and Martin for lowpressure gas analysis, used in conjunction with improved apparatus for vacuum fusion gas extraction, collection and measurement, has been in constant use during the period under review for the determina-

* Commonwealth of Australia: Department of Supply. Australian Defence Scientiflc Service, Annual Report of Defence Standards Laboratories for the year ended 30th June, 1961, Pp. 49.
byrnong, Victoria: Defence Standards Laboratories, 1962.) tion of the gas content of chromium metal and chromium alloys by the vacuum fusion method.

During the year, major improvements were made to the control system of the air-conducting plant of the metrology laboratory in the Physics Division to enable temperatures in the Length Standards Room to be maintained at $20^{\circ} \mathrm{C} \pm 1^{\circ} \mathrm{C}$ irrespective of external conditions. Considerable developments in the application of interferometry to measurements of length are reported. A Varian wide-line nuclear magnetic resonance spectrometer with associated electromagnet and power supply has been installed, and is being used to investigate the concentration of the fluoride catalyst in the chromic acid solutions used in the production of chromium. Electron spin resonance has been used to study the defects produced. by $\gamma$-rays on a commercial polymethyl methacrylate. New values for $X$ - and $\gamma$-radiation absorption coefficients have been obtained, and designs for counters for the detection of soft X-rays have been developed and constructed.

The Metallurgy Division has been largely concerned with the evaluation of one of the Australian chromiumbased high-temperature alloys processed under quasiindustrial conditions. This includes ductility studies, internal friction measurements and observations of the creep behaviour. Work has continued on cleavage in cast molybdenum of high purity and in wrought chromium. As a contribution to the understanding of the abrasion of metals, the sliding of a metal specimen on silicon carbide abrasive papers has been studied, and it has been found that the majority of abrasive particles make a groove in the surface of the metal, piling up a ridge on either side, but removing little or no metal. An idealized model of the process has been devised and an expression obtained for the rate of removal of material with allowance made for the deterioration in use of the 